\title{
Clinical and psychological characteristics of propofol abusers in Korea: a survey of propofol abuse in 38, non-healthcare professionals
}

\author{
Eun-Jung Kim ${ }^{1}$, Seon-Hwa Kim ${ }^{1}$, Yang-Jin Hyun ${ }^{1}$, Yeon-Keun $\mathrm{Noh}^{2}$, \\ Ho-Sang Jung ${ }^{1}$, Soon-Young Han ${ }^{1}$, Chan-hye Park ${ }^{3}$, Byung Moon Choi ${ }^{3}$, \\ and Gyu-Jeong $\mathrm{Noh}^{3,4}$ \\ ${ }^{1}$ Korea Ministry of Food and Drug Safety, Cheongju, ${ }^{2}$ Incheon Namdong Police Station, Incheon, Departments of \\ ${ }^{3}$ Anesthesiology and Pain Medicine, ${ }^{4}$ Clinical Pharmacology and Therapeutics, Asan Medical Center, University of \\ Ulsan College of Medicine, Seoul, Korea
}

Background: The aim of this study is to investigate the characteristics of propofol abuse based on the results of a survey analysis of abusers among non-healthcare professionals in Korea.

Methods: Thirty-eight propofol abusers were questioned between October and December 2010, and were enrolled and voluntarily participated in a structured survey consisting of an interview and completing a previously prepared questionnaire. The questionnaire was divided into three distinct parts: part 1 dealt with the history of propofol abuse; part 2 highlighted the problems caused by propofol abuse; and part 3 enquired regarding demographics of abusers.

Results: Thirty-one (81.6\%) of the 38 interviewees abused propofol for more than one year. During the last 12 months, 34 (89.0\%) received propofol at two or three times a week. The minimum and maximum amounts of propofol (median, range) administered each time were $500(100,1000)$ and $2000(500,4000) \mathrm{mg}$, respectively. Stress relief and the maintenance of a sense of well-being were quoted the most important reasons for the first-time administration of propofol and its subsequent abuse, respectively. The majority of abusers (36.0, 97.3\%) reported a sense of pleasure or euphoria at the time of their propofol injection. Withdrawal symptoms occurred in five abusers (13.2\%). Thirteen (36.1\%) reported disruptions in their work life. None of the respondents had previously admitted to and or reported abuse of any other controlled substances.

Conclusions: These results provided reference data for the regulation of propofol in Korea as a controlled substance and may also be of interest to international agencies in other countries.

Key Words: Abuse, General population, Propofol.

Corresponding author: Gyu-Jeong Noh, M.D., Ph.D.

Departments of Anesthesiology and Pain Medicine, Clinical Pharmacology and Therapeutics, Asan Medical Center, University of Ulsan College of Medicine, 88, Olympic-ro 43-gil, Songpa-gu, Seoul 05505, Korea

Tel: 82-2-3010-3855, Fax: 82-2-3010-6790

E-mail: nohgj@amc.seoul.kr

Received: March 4, 2015. Revised: 1st, May 7, 2015; 2nd, July 22, 2015. Accepted: August 18, 2015.

Korean J Anesthesiol 2015 December 68(6): 586-593

http://dx.doi.org/10.4097/kjae.2015.68.6.586

(c) This is an open-access article distributed under the terms of the Creative Commons Attribution Non-Commercial License (http://creativecommons.org/ licenses/by-nc/4.0/), which permits unrestricted non-commercial use, distribution, and reproduction in any medium, provided the original work is properly cited. 


\section{Introduction}

Propofol (2, 6-diisopropylphenol) can be used as an intravenous sedative and hypnotic agent due to the rapid onset and short duration of its action. As established in molecular [1], animal [2], and human [3] pharmacological studies, propofol has a significant potential to become a drug that may be easily obtained and abused. However, it has not yet been designated as a controlled substance anywhere in the world except in Korea. The intense media attention that followed the propofol-related death of Michael Jackson in 2009 unfortunately resulted in an increased awareness of propofol's potential as a source of drug abuse by the general population. In February, 2011, the Korea Ministry of Food and Drug Safety (MFDS) designated propofol as a psychotropic drug, and thus mandating its regulation under the Controlled Substance Act [4].

All psycotropic drugs act on the ventral tegmental area (VTA) of the midbrain and the nucleus accumbens (NAc) of the limbic forebrain, and thus enhancing dopaminergic transmission or exerting dopamine-like effects in the VTA-NAc pathway [5]. An in vivo brain microdialysis study in rats showed that propofol, in nanomolar doses increased the discharge and excitatory transmission of dopamine neurons in the VTA [6] as well as the concentration of dopamine in the NAc [1]. These findings suggest the potential for propofol abuse by humans in whom the symptoms of addiction, including euphoria, calmness, anxiety relief, and restfulness, may occur.

Most of the literature reports regarding the misuse and abuse of propofol are case reports in which the abusers were healthcare professionals, especially anesthesiologists, physicians, and nurses [7-14]. In those reports, propofol was reported to be abused either for recreational purposes, for stress relief or for insomnia [15]. Although rare, there were two case reports regarding propofol abuse by non-healthcare professionals who received

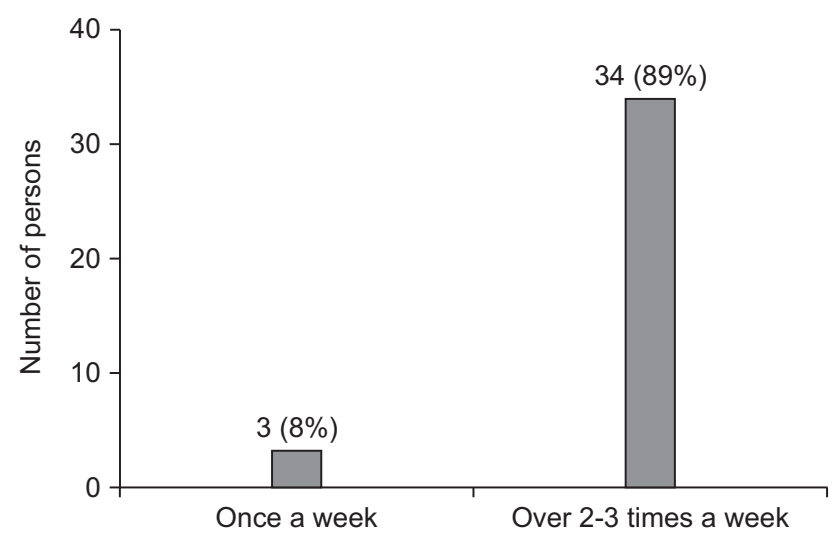

propofol for the treatment of tension headaches [16,17].

In contrast, a comprehensive analysis of propofol abuse, including the frequency, duration, amount, and reasons, in the general population, that is, other than healthcare providers and patients treated with propofol, does not exist in the published literature.

Therefore, the purpose of our study is to investigate and report the specific characteristics of propofol abuse based on a survey of abusers among non-healthcare professionals.

\section{Materials and Methods}

A total of 45 propofol abusers (non-healthcare professionals) were asked to participate in a survey with the aid of the Namdong Police (Incheon, Korea) in order to secure an abuser list. The MFDS conducted this survey between October and December 2010 .

Among the 45 abusers, 38 consented to publication of their information for scientific purposes. The demographics of these 38, non-healthcare professionals are detailed in Table 1. The questionnaire was subdivided into three parts as shown in the Appendix:

Table 1. Characteristics of Propofol Abusers $(n=38)$

\begin{tabular}{ll}
\hline Age & $28.8 \pm 2.7$ \\
Male/Female & $3(7.9 \%) / 35(92.1 \%)$ \\
Not married/married & $35(92.1 \%) / 3(7.9 \%)$ \\
Occupation & Employee in adult entertainment \\
& establishments: $29(76.3 \%)$ \\
& Unemployed: $6(15.8 \%)$ \\
& Self-employed: $3(7.9 \%)$ \\
Highest level of education & High school: $28(73.7 \%)$ \\
& College or university: $10(26.3 \%)$
\end{tabular}

Data are presented as the mean \pm SD or count (\%) as appropriate.

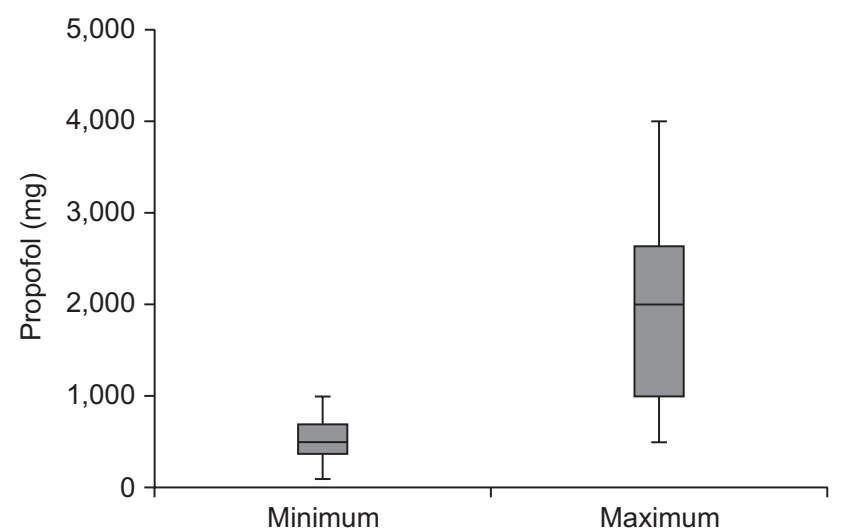

Fig. 1. Frequency of abuse (left panel) and amount of propofol at each administration (right panel) during the last 12 months. On the right panel, minimum and maximum on the y axis indicate the lowest and highest amounts of propofol for each individual. The boxes indicate 25th, 50th, and 75th percentiles, while whiskers, the minimum and maximum. One abuser had no comment regarding the frequency of the abuse. 
- Part 1 dealt with the history of propofol abuse and was designed to obtain general information regarding an individual's history of propofol abuse;

- Part 2 attempted to identify the problems caused by propofol abuse; the second part attempted to identify the social and economic problems caused by the abuse; and

- Part 3 recorded the demographics of the interviewed abusers. Statistical analysis was carried out using SigmaStat 3.5 for Windows (Systat Software, Inc., Chicago, IL, USA). The data are expressed as the mean (SD) for normally distributed continuous variables, the median (range) for abnormally distributed continuous variables, and the counts and percentages for the categorical variables.

\section{Results}

Although the indications are that propofol abusers may be adult entertainment workers, a small percentage of the more famous entertainment workers, including celebrities as well as healthcare professionals, have been reported to abuse propofol. However, most of the participants in this survey were from adult entertainment establishments and volunteered their participation.

Among the 38 propofol abusers, 31 (81.6\%) abused propofol for $>1$ year, five (13.2\%), for 3-6 months, and two (5.3\%) for $<3$ months. The frequency of propofol abuse as well as the amount injected each time during the last 12 months are shown in Fig. 1. The minimum and maximum amounts of propofol (median, range) administered each time were $500(100,1000)$ and 2000 $(500,4000) \mathrm{mg}$, respectively, and thus implying that abusers needed a large amount of the drug to satisfy their craving or specific needs.

The degree of pleasure or euphoria derived from propofol abuse, as reported by the interviewees, is graphically represented

\section{A}

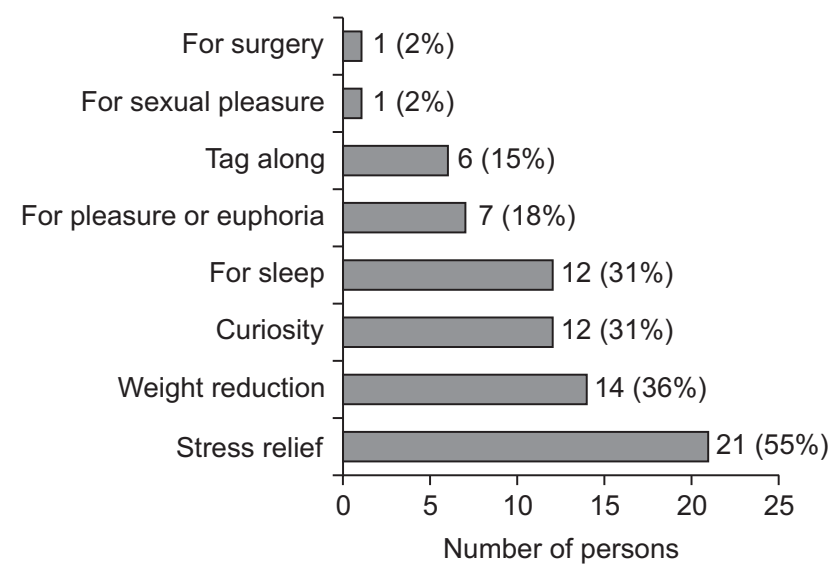

in Fig. 2. The majority of abusers (36/37, 97.3\%) reported experiencing pleasure or euphoria at the time of their propofol injection. However, $31.6 \%$ of the interviewees responded as having a very low or low degree of pleasure or euphoria.

Fig. 3 shows the reasons for the first administration of propofol and for its subsequent abuse. The abusers highlighted that stress relief and the maintenance of a sense of well-being were the most common reasons for their first experimentation with propofol and the continued abuse of the drug. It was further noted that withdrawal symptoms had occurred in five (13.2\%) of the abusers (Fig. 4). These symptoms manifested in the form of anxiety $(2,5.3 \%)$ and sleep disturbances $(3,7.9 \%)$ which included either insomnia or hypersomnia (Fig. 4). A comparison of the frequency, duration of propofol infusion, amount of propofol at each administration, and the demographics of propofol abusers with and without withdrawal symptoms are summarized in Table 2. However, disturbed human relationships or psychobehavioral problems were not reported in the majority of abusers $(33 / 38,87.0 \%$, and $31 / 36,86.0 \%$, respectively). Thirteen

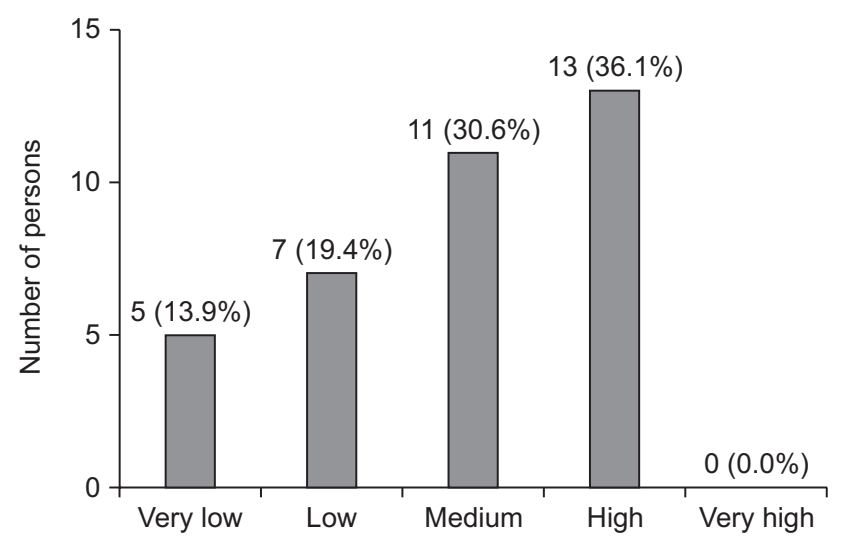

Fig. 2. Degree of pleasure or euphoria obtained from propofol abuse.

B

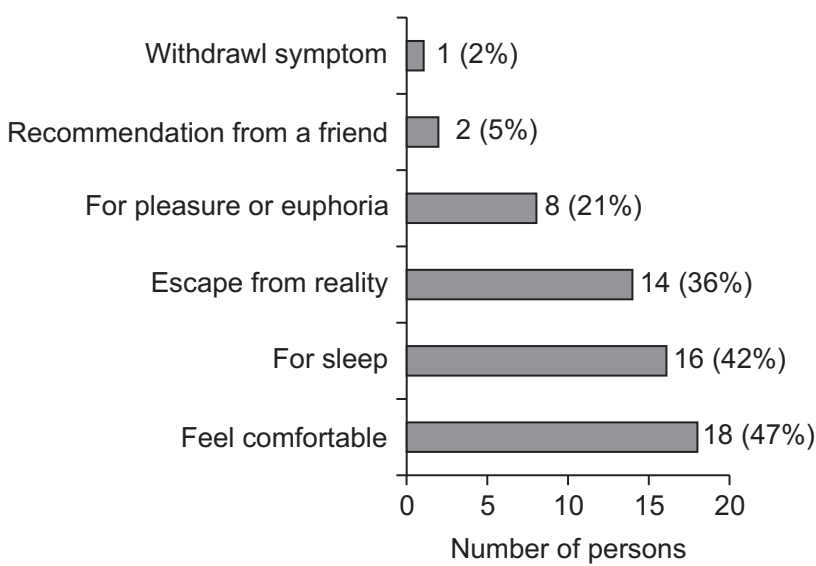

Fig. 3. Reasons for the first administration of propofol (A) and for its subsequent abuse (B). 
A

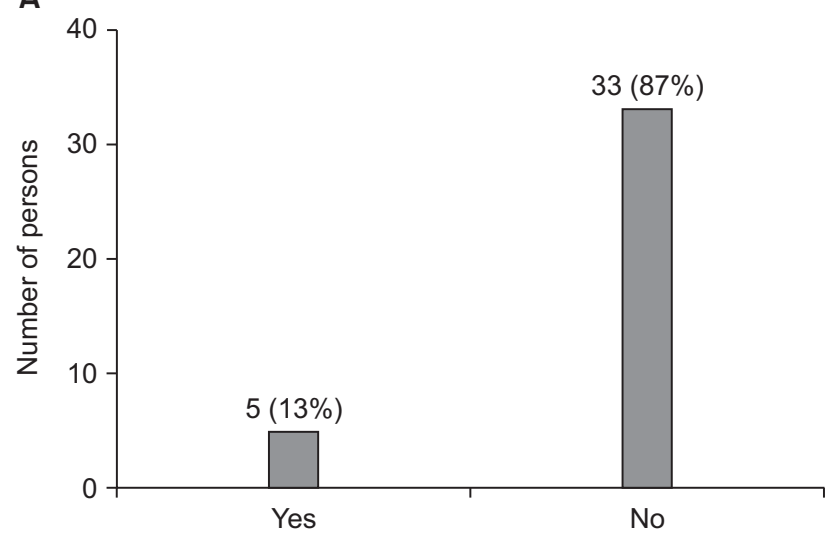

B

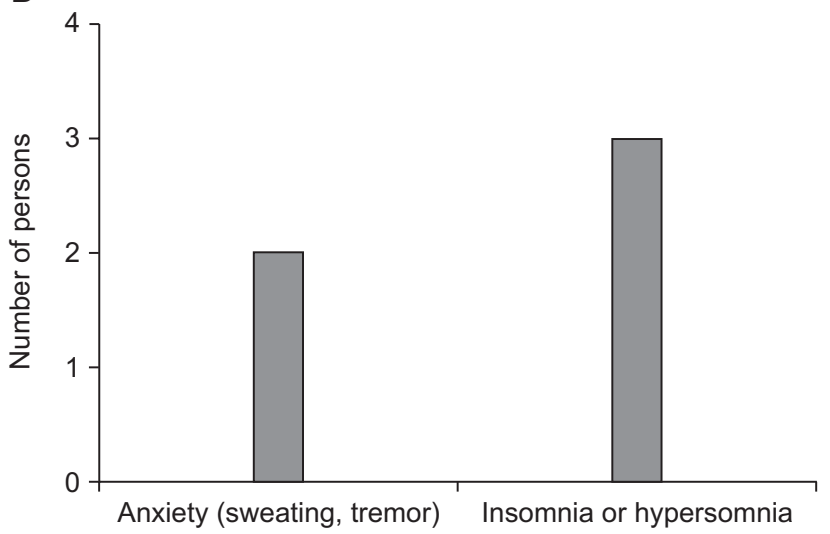

Fig. 4. The count of abusers who experienced withdrawal symptoms (A) and the type of withdrawal symptoms (B).

Table 2. Comparison of the Frequency and Duration of Propofol Infusion, Amount of Propofol at Each Administration, and Demographics in Propofol Abusers with and without Withdrawal Symptoms

\begin{tabular}{lcc}
\hline & $\begin{array}{c}\text { Propofol abusers with } \\
\text { withdrawal symptoms }(\mathrm{n}=5)\end{array}$ & $\begin{array}{c}\text { Propofol abusers without } \\
\text { withdrawal symptoms }(\mathrm{n}=33)\end{array}$ \\
\hline $\begin{array}{l}\text { Frequency of abuse } \\
\text { Two or three a week (n) }\end{array}$ & $5(100)$ & $30(91)$ \\
$\begin{array}{l}\text { Duration of abuse } \\
\text { Over one year }\end{array}$ & $5(100)$ & $28(85)$ \\
Amount of propofol at each administration & & $533 \pm 261$ \\
$\quad$ Minimum (mg) & $520 \pm 148$ & $2000(1375-3000)$ \\
Maximum (mg) & $1200(875-2000)$ & $30 / 3$ \\
Female/Male & $5 / 0$ & $29.1 \pm 2.7$ \\
Age (yr) & $26.6 \pm 1.9$ & \\
\hline
\end{tabular}

Data are presented as the mean \pm SD, median (25-75\%) or count (\%) as appropriate. These parameters were compared using the two-sample t-test, Mann-Whitney rank-sum test or the $\chi^{2}$ test as appropriate. No significant differences between propofol abusers with and without withdrawal symptoms were found in any of the observations.

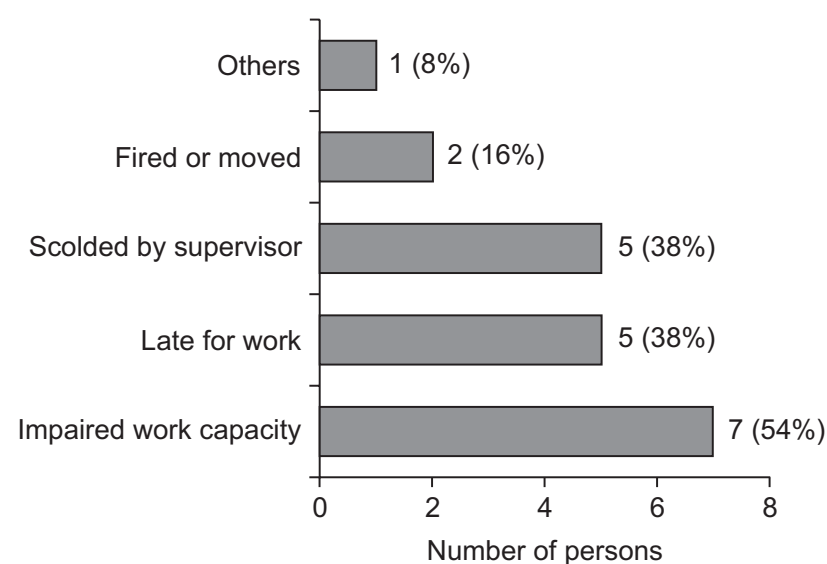

Fig. 5. Workplace disruptions reported by propofol abusers. Thirteen (36.1\%) abusers complained of disruptions in their work life. Multiple answers were possible for this question.
(36.1\%) abusers complained of disruptions to their work life, as specifically described in Fig. 5. Fifty percent of the respondents (19) had attempted to quit the propofol habit, and 22 (58\%) had suffered economic stress as a result of their abuse. However, none of the respondents had reported or acknowledged abuse of any other addictive substances or drugs.

\section{Discussion}

The majority of the interviewees abused propofol for more than one year, and two or three times a week during the last 12 months. Stress relief and the maintenance of a sense of well-being were the most important reasons for the first-time administration of propofol and for its subsequent abuse. The median minimum and maximum doses of propofol (range) administered each time were $500(100,1,000)$ and $2,000(500,4,000) \mathrm{mg}$, respectively. Withdrawal symptoms occurred in five abusers (13.2\%). 
The results of this survey, although from a small sample population, may provide characteristics of propofol abusers in Korea who are non-healthcare professionals. Most of the people enrolled in this survey were single women in their 20 s, and which seemed to have occurred for a few, specific reasons. Some immoral doctors had managed specialized private hospitals to administer propofol to non-healthcare professionals who were without a need for medical care. Some non-healthcare professionals who were under extreme stress, especially employees in adult entertainment establishments, relieved their stress by being kept under sedation induced by the continuous infusion of propofol. After the procedure most people felt a new sense of well-being, euphoria, and a sensation of having had sound sleep and shared this experience with their friends and co-workers. They then habitually visited the hospitals in order to meet their needs and became addicted to propofol. Fortunately, serious complications induced by continuous infusion of propofol, such as hypoxic brain damage, were not observed in these abusers because health care providers administered propofol.

Withdrawal symptoms of propofol were reported in some case reports in which psychotic symptoms, including hallucinations, agitation, and confusion, and physical symptoms, such as tachycardia, tachypnea, tremor, and hyperpyrexia, were observed [18-20]. In our study, psychological symptoms (anxiety) and physical symptoms (sweating, tremor, insomnia, and hypersomnia) were also observed. As is seen in Table 2, the frequency, duration of propofol infusion, the amount of propofol at each administration, and the demographics of propofol abusers did not show significant differences between abusers with and without withdrawal symptoms. The patients in published case reports differ in the duration of their propofol administration, age, and outcome [18-20]. It seems to be difficult to suggest accurate information regarding the prevention of propofol withdrawal symptoms, given the limited published data. However, all of the abusers in our study who experienced propofol withdrawal symptoms were single women in their 20 s and with propofol administration two or three times a week for over one year.

Most of the abusers in our study felt pleasure or euphoria at the time of their propofol injection, and which did not coincide with previous reports in which patients receiving propofol often experienced euphoria during their recovery [21,22]. However, abusers have described their pleasant or euphoric experience after the injection of propofol $[11,16,17,23]$. This discrepancy may be explained by the psychological expectation of propofol administration in propofol abusers. In particular, propofol was continuously infused, instead of a bolus injection, in abusers in this study, and thus resulted in insignificant pain upon injection with propofol.

The propensity for propofol abuse by non-healthcare professionals had been highlighted in Korea in some very high profile cases specifically from the entertainment industry. In general, as reported in some cases, non-healthcare professionals who became highly dependent on propofol have embarked on the use of some ingenious tactics such as to seek admission to the hospitals and undergoing unnecessary tests or treatment such as gastroduodenoscopies, colonoscopy or cosmetic surgery, those being procedures in which propofol is typically administered as a hypnotic. As propofol abuse in non-healthcare professionals has come to the fore as a social issue with the potential to escalate and increase, in February of 2011 the MFDS became the first such agency in the world to designate propofol as a controlled substance, mandating control in its manufacture, distribution, storage, and use. However, some healthcare professionals were concerned that propofol regulation would be an obstacle preventing its readily available use in urgent and emergent clinical settings. However, the goal of the MFDS was to avoid the potential for the abuse and misuse of propofol rather than to curtail its ready availability in clinical situations. The results of this survey were taken into consideration by the MFDS in designating propofol as a controlled substance and in their efforts to control its abuse in Korea. When the MFDS held a public hearing regarding propofol regulation, the results contributed to putting more weight on the avoidance of the potential for the abuse and misuse of propofol rather than on curtailing its easy access in clinical situation. To the best of our knowledge, no other country in the world has taken similar actions. It may be debated that an exception may be the United States of America where, on November 5, 2009, their Drug Enforcement Administration classified fospropofol, the water-soluble prodrug of propofol, as a controlled substance (Schedule IV) [24].

The reasons why other counties did not designate propofol as a controlled substance may be explained by two ways. First, propofol abuse in non-healthcare professionals has not yet become a social issue. Second, more serious substance abuse, including narcotics and marijuana, may receive attention from the regulatory body in each country. Since February of 2011, the pharmaceutical companies in Korea that manufacture or import propofol should regularly report the amount of their production or importation to the MFDS. The MFDS also periodically inspects those companies in order to check the sales volume of propofol. In hospitals, propofol must be secured in a locked environment requiring key access and wastage must be documented in the wastage records. We cannot obtain objective data regarding any change in the overall frequency of propofol abuse. However, since propofol was designated to a controlled substance, the criteria regarding propofol management, including its storage and use, have been strengthened, and resulting in difficult access of propofol for local healthcare providers. The overall propofol abuse in non-healthcare professionals will probably not increase after the propofol regulation. 
In conclusion, these results provide reference data for the regulation of propofol as a controlled substance in Korea and may also be of interest to international agencies in other countries.

\section{Declaration of Interest}

All of the authors have completed the Unified Competing Interest form and declare that they have no competing interests.

\section{References}

1. Pain L, Gobaille S, Schleef C, Aunis D, Oberling P. In vivo dopamine measurements in the nucleus accumbens after nonanesthetic and anesthetic doses of propofol in rats. Anesth Analg 2002; 95: 915-9.

2. Pain L, Oberling P, Sandner G, Di Scala G. Effect of propofol on affective state as assessed by place conditioning paradigm in rats. Anesthesiology 1996; 85: 121-8.

3. Zacny JP, Lichtor JL, Thompson W, Apfelbaum JL. Propofol at a subanesthetic dose may have abuse potential in healthy volunteers. Anesth Analg 1993; 77: 544-52.

4. Psychotic drugs control act. Act No. 5529, 28 Feb 1998. Available from http://www.moleg.go.kr/lawinfo/engLawInfo;jsessionid=RCuRlvvr9 hpcP1sHpsKfkdWmDc8d1DeMgUrwutQo4npebIeTevh3XWVD3t0Wdm4s.moleg_a1_servlet_engine2?.pstSeq=58352\&pageIndex=4.

5. Nestler EJ. The neurobiology of cocaine addiction. Sci Pract Perspect 2005; 3: 4-10.

6. Li KY, Xiao C, Xiong M, Delphin E, Ye JH. Nanomolar propofol stimulates glutamate transmission to dopamine neurons: a possible mechanism of abuse potential? J Pharmacol Exp Ther 2008; 325: 165-74.

7. Iwersen-Bergmann S, Rösner P, Kühnau HC, Junge M, Schmoldt A. Death after excessive propofol abuse. Int J Legal Med 2001; $114: 248-51$.

8. Drummer OH. A fatality due to propofol poisoning. J Forensic Sci 1992; 37: 1186-9.

9. Gündel H, Kuhs H. A case report on a 9-day-long abuse of propofol. Anasthesiol Intensivmed Notfallmed Schmerzther 1992; $27: 181-2$.

10. Follette JW, Farley WJ. Anesthesiologist addicted to propofol. Anesthesiology 1992; 77: 817-8.

11. Soyka M, Sch utz CG. Propofol dependency. Addiction 1997; 92: 1369-70.

12. Odell M. Propofol abuse. Anaesth Intensive Care 1999; 27: 539.

13. Cirimele V, Kintz P, Doray S, Ludes B. Determination of chronic abuse of the anaesthetic agents midazolam and propofol as demonstrated by hair analysis. Int J Legal Med 2002; 116: 54-7.

14. Roussin A, Mirepoix M, Lassabe G, Dumestre-Toulet V, Gardette V, Montastruc JL, et al. Death related to a recreational abuse of propofol at therapeutic dose range. Br J Anaesth 2006; 97: 268.

15. Roussin A, Montastruc JL, Lapeyre-Mestre M. Pharmacological and clinical evidences on the potential for abuse and dependence of propofol: a review of the literature. Fundam Clin Pharmacol 2007; 21: 459-66.

16. Fritz GA, Niemczyk WE. Propofol dependency in a lay person. Anesthesiology 2002; 96: 505-6.

17. Schneider U, Rada D, Rollnik JD, Passie T, Emrich HM. Propofol dependency after treatment of tension headache. Addict Biol 2001; 6: 263-5.

18. Cawley MJ, Guse TM, Laroia A, Haith LR, Ackerman BH. Propofol withdrawal syndrome in an adult patient with thermal injury. Pharmacotherapy 2003; 23: 933-9.

19. Valente JF, Anderson GL, Branson RD, Johnson DJ, Davis K Jr, Porembka DT. Disadvantages of prolonged propofol sedation in the critical care unit. Crit Care Med 1994; 22: 710-2.

20. Au J, Walker WS, Scott DH. Withdrawal syndrome after propofol infusion. Anaesthesia 1990; 45: 741-2.

21. Brandner B, Blagrove M, McCallum G, Bromley LM. Dreams, images and emotions associated with propofol anaesthesia. Anaesthesia 1997; 52: $750-5$

22. Hunter DN, Thornily A, Whitburn R. Arousal from propofol. Anaesthesia 1987; 42: 1128-9.

23. Bonnet U, Harkener J, Scherbaum N. A case report of propofol dependence in a physician. J Psychoactive Drugs 2008; 40: 215-7.

24. Schedules of Controlled Substances: Placement of Fospropofol Into Schedule IV, Drug Enforcement Administration. Proposed Rule. 2009, pp 36424-7. 


\section{Appendix}

\section{Part I. History of propofol abuse}

1. For how long have you abused propofol?

$\square$ Less than 1 month, $\square 3$ months, $\square 6$ months, $\square$ Over 1 year

2. How often did you abuse propofol during the last 12 months?

$\square 2$ or 3 times a week, $\square$ Once a week, $\square 2$ or 3 times a month, $\square$ Once a month, $\square$ Less than once during 3 the past months

3. How much propofol did you intake during each abuse episode?

Minimum (mg):

Maximum (mg):

4. Why did you abuse propofol?

$\square$ Curiosity, $\square$ Recommendation from a friend, $\square$ Tag along, $\square$ Stress relief, $\square$ Weight reduction,

$\square$ For sleep, $\square$ For pleasure or euphoria, $\square$ For sexual pleasure, $\square$ Other

5. Have you ever tried to stop abusing propofol?

$\square$ Yes, $\square$ No

6. If you failed to quit abusing propofol, why did this happen?

$\square$ For pleasure or euphoria, $\square$ Feeling comfortable, $\square$ Recommendation from a friend, $\square$ Escape from reality,

$\square$ For sleep, $\square$ Social inadaptability (alienation, isolation, etc.), $\square$ Withdrawal symptoms, $\square$ Other

7. When during propofol administration do you feel pleasure or euphoria?

During its injection

$\square$ During recovery from sedation or anesthesia

$\square$ Other

8. Describe the degree of pleasure or euphoria you feel during propofol administration?

$\square$ Very low, $\square$ Low, $\square$ Medium, $\square$ High, $\square$ Very high

9. Have you experienced any withdrawal symptoms?

$\square$ Yes, $\square$ No

10. If yes, what kinds of withdrawal symptoms have you experienced (more than one answer may be checked)?

$\square$ Anxiety (sweat, essential tremor, etc.), $\square$ Visual or auditory hallucinations, $\square$ Visual distortion, $\square$ Headache or other pain,

$\square$ Sleep disturbances (insomnia or somnolence for a few days), $\square$ Other

11. Have you abused any other substances or drugs in the past?

$\square$ Yes, $\square$ No

\section{Part II. Problems caused by propofol abuse}

1. Do you have any problems in human relationships as a result of your propofol abuse?

$\square$ Yes, $\square$ No

2. What kinds of financial problems were (or are) you faced with?

I could (can) not pay off the debts incurred as a result of propofol abuse

My credit worthiness has been downgraded

$\square$ I sold my possessions and valuables, such as my house etc., to obtain money for my propofol dependency

$\square$ Propofol abuse drove me into bankruptcy

$\square$ Other 
3. Do you have any career problems caused by propofol abuse?

$\square$ Impaired work capacity

$\square$ Late for work

$\square$ Scolded by supervisor

$\square$ Fired or moved

$\square$ Did not get promoted

$\square$ Other

4. Do you have any physical or psychological problems caused by propofol abuse?

$\square$ Yes, $\square$ No

5. What physical or psychological problem(s) have you experienced? Please describe it (or them) specifically.

\section{Part III. Personal history}

1. Age:

2. Sex

$\square$ Male, $\square$ Female

3. Highest level of education completed:

$\square$ Elementary school

$\square$ Junior high school

$\square$ High school

$\square$ University (or college)

$\square$ Graduate school

4. Marital status

$\square$ Unmarried, $\square$ Married, $\square$ Divorced, $\square$ Remarried

\section{Occupation}

$\square$ Unemployed, $\square$ Employee in adult entertainment establishment, $\square$ Housewife, $\square$ Self-employed,

$\square$ Entertainer or athlete, $\square$ Student, $\square$ Laborer, $\square$ Office worker, $\square$ Medical professional, $\square$ Other 